\title{
Ecological Scarcity Method: Adaptation and Implementation for Different Countries
}

\author{
Marina Grinberg ${ }^{1}$, Robert Ackermann ${ }^{2}$, Matthias Finkbeiner ${ }^{3},{ }^{1-3}$ Department of Environmental Technology, \\ Technische Universität Berlin
}

\begin{abstract}
The Ecological Scarcity Method is one of the methods for impact assessment in LCA. It enables to express different environmental impacts in single score units, eco-points. Such results are handy for decision-makers in policy or enterprises to improve environmental management.

So far this method is mostly used in the country of its origin, Switzerland. Eco-factors derive from the national conditions. For other countries sometimes it is impossible to calculate all ecofactors. The solution of the problem is to create a set of transformation rules. The rules should take into account the regional differences, the level of society development, the grade of scarcity and other factors. The research is focused on the creation of transformation rules between Switzerland, Germany and the Russian Federation in case of GHG emissions.
\end{abstract}

Keywords - Life Cycle Impact assessment, Ecological Scarcity Method, transformation rule, greenhouse gases

\section{INTRODUCTION}

The Ecological Scarcity Method was developed in Switzerland. The first version was published in 1990. In 2006 it was updated in accordance to ISO 14044: Environmental management -- Life cycle assessment -- Requirements and guidelines [1].

The formula is used in the Swiss ecological scarcity method [2]:

$$
\text { Eco }- \text { factor }=K \cdot \frac{1 \cdot E P}{F_{n}} \cdot\left(\frac{F}{F_{k}}\right)^{2} \cdot c
$$

where

K-Characterization factor of a pollutant or of a resource; $\mathrm{F}_{\mathrm{n}}$-Normalization flow: current annual flow, with Switzerland as system boundary;

F-Current flow: current annual flow in the reference area;

$\mathrm{F}_{\mathrm{k}}$-Critical flow: critical annual flow in the reference area; c-Constant (10 $12 / a)$;

EP-Eco-point: the unit of the assessed result.

The method is used for the Life Cycle Assessment (LCA) of products and processes. Often the results of LCA are presented as an inventory table with amounts of resource use and pollution amounts. It is difficult to compare if a product or a process gives rise to very different types of emissions [3].

Miyazaki N. in his paper "Applying EcoBalance to Management Control: Combining Economic and Ecological Accounting" formulated the core of the idea in the following form:
Environmental impact* Eco-factor=Environmental Impact

$\begin{array}{lll}\text { in Physical Units } & (E P / \mathrm{kg}, & \text { in } E P \\ (\mathrm{~kg}, \mathrm{~m} 3, \text { etc }) & E P / \mathrm{m3}, \text { etc })\end{array}$

The eco-factors (Ecological Impact Factors), are expressed as EP (Eco-point) $/ \mathrm{kg}$ or EP/m3, and work as weighting factors to indicate the degree of damage to the environment, which normally consists of various kinds of environmental impacts [4].

The application of the method gives the opportunity to present different environmental impacts in the same units, ecopoints (EP). The latter means that it is easier to see the share of each category in the overall result and set the plan of actions toward the reduction of the most negative ones. Thereby, the method assists environmental management and decision making.

\section{SPREAD OF THE METHOD}

The Swiss Method has spread to several European countries in the 1990s, but the most widespread dissemination has been in Japan. Based on the EcoScarcity method, a group of researchers under the chair of Prof. Dr. Nobuyuki Miyazaki and Prof. Claude Siegenthaler developed the JEPIX (Environmental Policy Priorities Index for Japan) Method, which was published in 2004. JEPIX covers different environmental aspects, such as global warming, ozone depletion, water quality, waste management, noise and others. It shows that the concept can be used to establish an Ecological Scarcity Method valid for other nations or political entities.

The current version of the EcoScarcity method, however, is mostly oriented on internal use. All impacts are assessed from a Swiss perspective. The life cycle of the product includes different stages. The usual situation is that raw materials can be extracted in one country, production process takes place in the second one and disposal in the third. Having eco-factors for substances for different countries could make the result more objective and full, because different countries have different environmental pressures. The assumption that the pollutants are deposited in the same area where they are emitted makes the Eco-factors specific to the region for which they are calculated [2].

The calculation of eco-factors demands flows data and its careful analyse. The two main parts of the formula (1) are flows of pollutants or consumed resource. The critical flow 
derives from national legislation, international agreements and approaches to a sustainable level of environment. The actual flow shows the current environmental situation. Unfortunately, sometimes it is not possible to get information about current flow of emissions or political targets since these are not clear enough for some pollution categories, which makes the calculation of eco-factors more difficult and sometimes even impossible. The creation of the set of transformation rules could advance the wider application of the Ecological Scarcity Method.
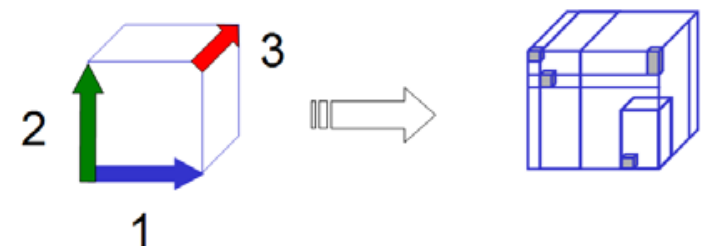

Fig. 1. 3D Model of Ecological Scarcity Method. Three dimensions on the right cube stand for 1) Eco-factor; 2) Substance; 3) Country. The left cube shows data sets of countries implemented EcoScarcity.

The model presented in Fig.1 shows which impact categories are assessed by different parties and which are not. For example, in Swiss EcoScarcity there are much more calculated Eco-factors than in JEPIX. But in JEPIX there is an eco-factor for road traffic noise, that is absent in the Swiss version. The reason for this is the difference in approaches between these two models. The development of transformation rules could set up favorable condition for unification and filling the gaps if it is needed because the selection of substances is guided by their ecological and political relevance.

\section{DRIVING FORCES FOR ENVIRONMENTAL LIMITATIONS}

Critical and actual flows are the key parts of the formula for eco-factors calculation (1). For each country the critical and actual flow are individual and stipulate national conditions.

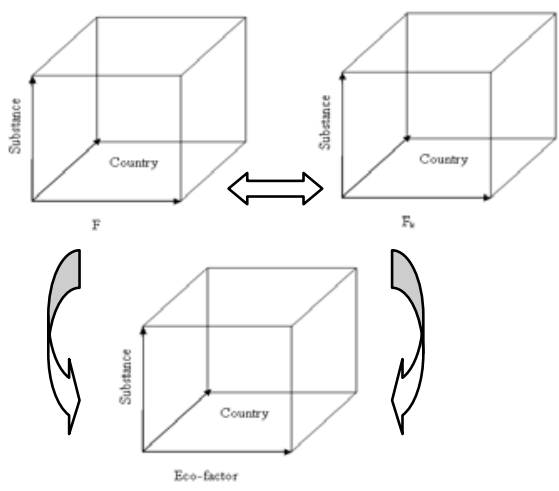

Fig. 2. Connection between Eco-factor and the flows of pollution or used resource (F-actual flow, Fk-critical flow)

According to the Ecological Scarcity Method: Eco-factors 2006, current flows are always to be determined with regard to the reduction target. The reference for the current and critical flows should be the same. Critical flows are generally based upon binding political targets which can be based on scientific findings. These are primarily protection targets established by law. Where no statutory provisions exist, critical flows are based upon political statements of intent with as binding a nature as possible. The EcoScarcity method allows some flexibility in choosing standards relevant to the purpose of the study.

To make the transformation rules appropriate it is necessary to define driving forces for limitation of one or another substance in different countries. In this paper the main focus is on defining transformation rules between Switzerland, Germany and the Russian Federation.

\section{A. Geographical differences}

Geographical differences between countries cover many aspects, such as area, climate, natural infrastructure, resource scarcity (fresh water, fossil fuels, ore, etc) and so on. Geographical settings may affect technologies [5].

One of the illustrations is type of energy used. Russia is one of the world's largest producers of energy, most of which it obtains from oil, natural gas and coal. The share of fossil fuels in overall electricity production is about $65 \%$, nuclear sources $16,5 \%$, hydropower $18 \%$, other renewable sources less then $1 \%$. In Germany the main source of electricity still remains coal. The share of fossil energy is $62 \%$, the share of electricity produced from renewable energy in Germany is more 20\%, almost half is energy of wind, and the other half -- from nuclear sources, however Germany will close all its nuclear reactors latest at the end of 2022. In Switzerland the structure of electricity production is the following: hydropower plants $56 \%$, nuclear power plants - 39\%, thermal power and other power plants - 5\%. As the energy sector remains the main source of greenhouse gas (GHG) emissions, the share of different sources makes sense.

Another example is waste management. The larger the available territory in a country, the easier it is to increase the area of landfills. That, in turn, affects the collection and recycling rates of wastes.

Geographical scope drives many decisions.

\section{B. Level of the society development}

As the critical flow derives from legislation, somehow it partly reflects the community priorities. According to [6], "socio-political drivers encompass the forces that influence decision making”.

Another important aspect is population rate and life expectancies, which are dependent on the quality of life and the environment. The population of Russia is 143,030,106 and life expectancy is 70 years. In Germany, the population is $82,329,758$ and the expectancy is 79 years, in Switzerland $7,866,500$ and 82 correspondingly. A lot of limitations of pollution flows are aimed not to damage human health. For example, dioxins and furans, those are highly toxic for human and may cause cancer. The limits for the substances are very strict as it commonly regarded as highly toxic environmental pollutants [7].

The EcoScarcity method includes such indicators as land use which is why the degree of urbanization is also important. High-income countries typically have populations that are 70- 
$80 \%$ urban [8]. . The structure of land use is changing as a consequence of the type of anthropogenic activity.

The level of society development drives scientific and technological development and has affects the level of environmental awareness [6].

\section{Economical development}

Economic growth and development depend on the increasing availability and mobility of resources, the efficiency with which they are used, and the institutional and policy environment [9]. Economic activity requires energy and physical inputs, some of which are ecosystem services to produce goods and services. By-products such as $\mathrm{CO}_{2}$ and other greenhouse gases, nutrients losses, and the waste stream can cause substantial ecosystem damage.

The boundaries among all categories of drivers are fluid, and they change with time, level of analysis, and observer [9]

\section{TRANSFORMATION RULE CONCEPT}

The transformation rule (TR) should advance the determination of the eco-factor for different nations if the direct calculation is not possible for some reason. Direct calculation is feasible if critical and actual flows are explicitly identified.

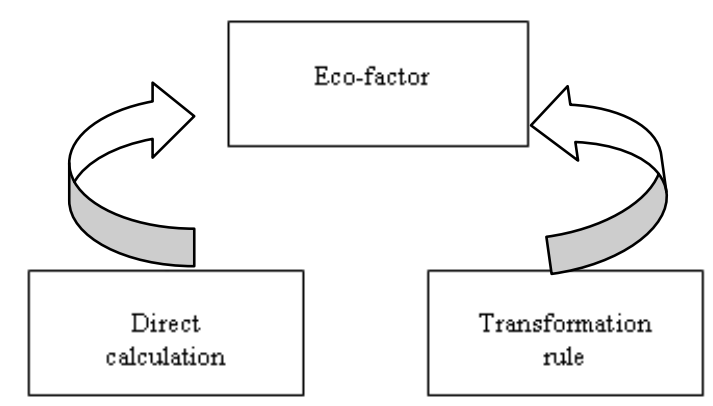

Fig. 3. Eco-factor determination

TR can be obtained as a coefficient between known ecofactor for Switzerland, for example, and the one that needs to be calculated.

Transformation rule should reflect the difference between the countries. Therefore TR in general is a function of national critical and actual flow. Critical and actual flows, in turn, are functions of driving forces.

Swiss Eco-factors 2006 includes information on more than 300 substances for different impact categories. It is obvious that eco-factors are individual and cannot be directly applied to another party. By having data sets at least for several categories, it is possible to get the trend between Eco-factors for the same substance but for diverse countries.

In the case of full data, the method of inverse adjusts the TR determination, as it shown in the example below. There are two ways as well: direct calculation difference between ecofactors and functionality analyze.
The idea of research is to define TR between Switzerland and Germany, Germany and Russia, and Switzerland and Russia (Fig. 4).

TR'

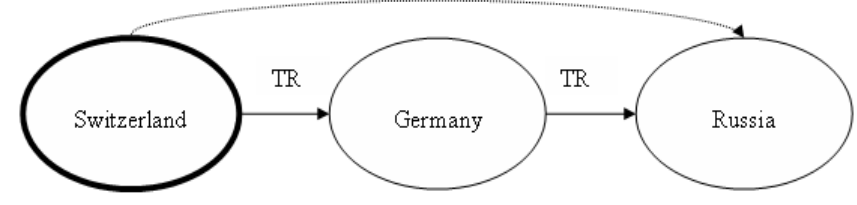

Fig. 4. Transformation rules between Russia, Germany and Switzerland.

It seems to be easier to define the TR between Switzerland and Germany first. Both countries have extensive environmental data bases and similarity in driving forces for limitation. The next step is application of the rule for Russian conditions. The transformation rule could be almost the same as for Germany (TR) or very specific (TR') (Fig. 4).

As a "check", TR rule can be applied to Japan as well. Japan calculated its own Eco-factors independently. The difference between JEPIX eco-factors and TR Eco-factors will show the level of correctness of one or another transformation rule.

\section{V.EXAMPLE: GHG}

Greenhouse gases contribute to global warming and consist of a great variety of substances. Among them, the most important substances are $\mathrm{CO}_{2}, \mathrm{CH}_{4}, \mathrm{NO}_{2}, \mathrm{SF}_{6}$ and various chlorinated and fluorinated hydrocarbons (CFCs, HCFCs, HFCs, PFCs).

The Kyoto Protocol is an international agreement linked to the United Nations Framework Convention on Climate Change (UNFCCC). The major feature of the Kyoto Protocol is that it sets binding targets for industrialized countries for reducing GHG emissions. The main aim of the Kyoto Protocol is to contain emissions of the main anthropogenic greenhouse gases in ways that reflect national differences in GHG emissions, wealth, and capacity to make the reductions. The protocol set up the principle of "common but differentiated responsibilities.”

The data for GHG emissions since 1990 are available for Germany, Russia and Switzerland. This means that Eco-factor could be directly calculated. But also it is possible to obtain the functions of critical and actual flows and provides the opportunity to get the TR based on the functions. Both ways are applicable and should give a similar result.

\section{A. Critical flow}

The Kyoto Protocol was signed by Switzerland in 1998. In 2001 the Climate Conference in Marrakech adopted the modalities for the implementation of the Protocol. The Swiss government then submitted the ratification to Parliament. The Council of States approved the ratification in December 2002 and the National Council in June 2003 (DETEC). 


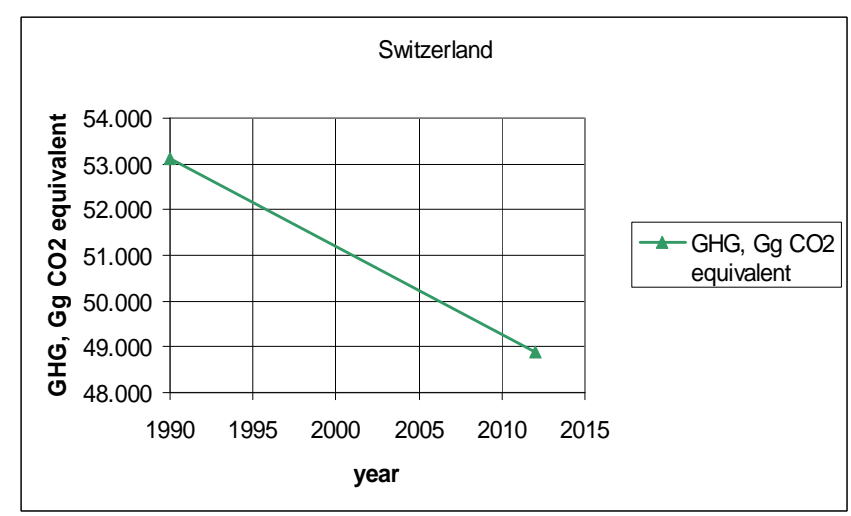

Fig. 5. Function of the critical flow of Switzerland according to Kyoto Protocol

According to the Kyoto protocol, Switzerland has to decrease the amount of greenhouse gases emissions by $8 \%$ of the base year 1990 (Fig. 5).

Germany is Europe's largest emitter of $\mathrm{CO}_{2}$. In March 2002, Germany ratified the Kyoto Protocol. Obligatory of Germany has a mandatory reduction of $21 \%$ GHG (Fig. 6).

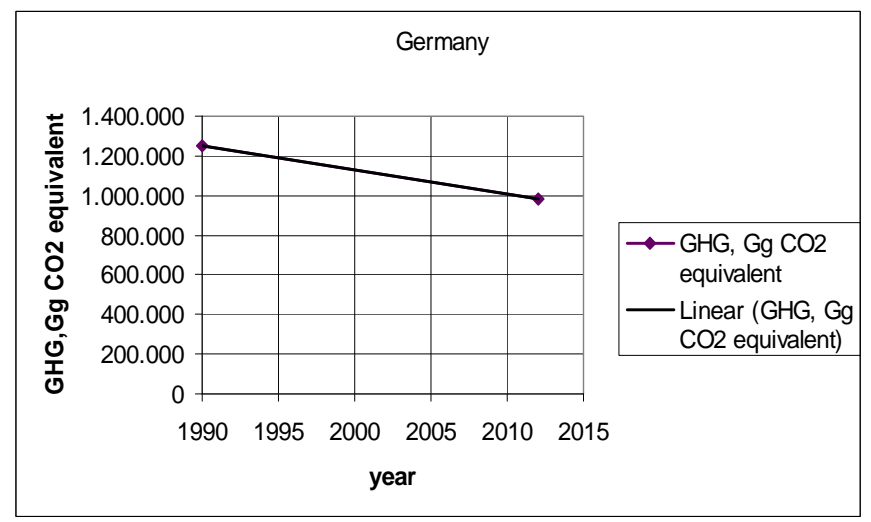

Fig. 6. Function of the critical flow of Germany according to Kyoto Protocol

The Russian Federation should keep the level of 1990 (Fig. 7). Russia officially notified the United Nations of Kyoto protocol ratification on 18 November 2004.

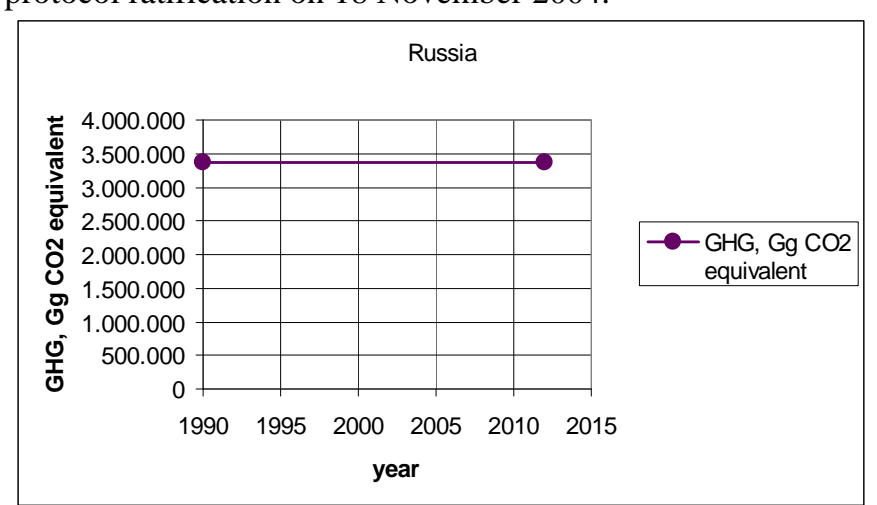

Fig. 7. Function of the critical flow of Russia according to Kyoto Protocol

Functions of critical flows have a linear character. The driving force for the GHG limitation has the same nature, as it derives from the same document for Russia, Germany and Switzerland.

$$
\begin{gathered}
f_{F k}^{\text {Russia }}=3369294,82 \\
f_{F k}^{\text {Germany }}=-11912 x+2 * 10^{7} \\
f_{F k}^{\text {Switzerland }_{F}}=-193,17 x+437528
\end{gathered}
$$

\section{B. Actual flow}

Data for actual flows derives from the official environmental statistic. In case of GHG, the data are taken from the UNFCC. Under the Protocol, a country's actual emissions have to be monitored and precisely recorded.

The top three sectors which contributed to GHG emission in Switzerland are: energy sector (80\%), agriculture (11\%) and industrial processes (6\%). The change in emissions from 1990 to 2009 is $-1.7 \%$.

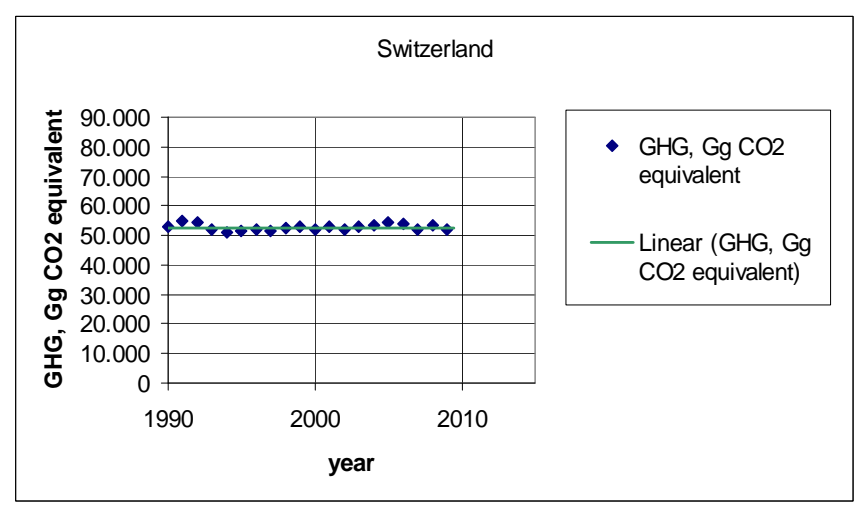

Fig. 8. Trend of GHG emission, Switzerland

The function of actual flow has a linear form and can be described as:

$$
f_{F}^{\text {Switzerland }}=2 x+48701
$$

For Germany the change from the level of 1990 in to 2009 was $-24,3 \%$. The main sectors remain energy (83\%), industrial processes (8\%) and agriculture (8\%).

The trend has a decreasing linear form:

$$
f_{F}^{\text {Germany }}=-13394 x+3 * 10^{7}
$$




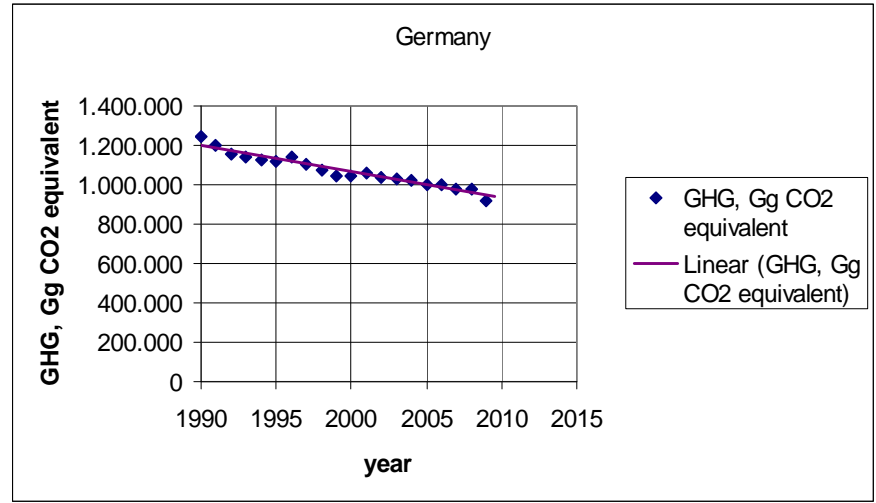

Fig. 9. Trend of GHG emission, Germany

The situation in the Russian Federation is the following: the reduction of GHG is $-38.9 \%$. Contribution from: energy sector is $82 \%$, industrial processes $-7.5 \%$, agriculture $-6.5 \%$. The share of waste in overall emissions has increased from 1.7 $\%$ to $3.5 \%$.

The trend has a complex form which can be described as a polynomial and linear function:

$$
\begin{gathered}
f^{\text {Russia }}{ }_{F 1}=8486,8 x^{2}-3 * 10^{7} x+3 * 10^{10} \\
f_{F 2}^{\text {Russia }}=-40599 x+8 * 10^{7}
\end{gathered}
$$

Figure 8 shows that the function of the trend of future GHG emission is not clear, it can have two different forms, polynomial and linear. In case of polynomial approximation, the future trend is increasing of GHG emission, in case of linear one - further reduction.

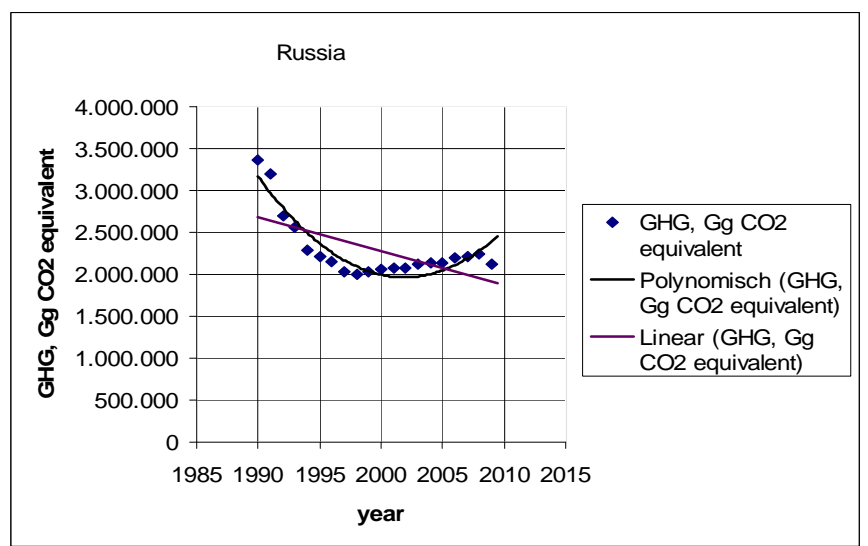

Fig. 10. Trend of GHG emission, Russia

Russia's reduced GHG emission is due primarily to economic collapse, leading to steep drops in energy demand and production, as well as other activities that lead to GHG emission. Many observers contend that climate change has not attracted the interest of high level leaders in Russia. On the other hand, on November 12, 2009, President Medvedev addressed the Federal Assembly and outlined his proposal for Russia to "undergo comprehensive modernization." In this speech Medvedev announced that "increasing energy efficiency and making the transition to a rational resource consumption model is another of our economy's modernization priorities.”

According to the UNFCCC review, in the period 19901998, GHG emissions in Russia decreased almost in parallel with the economic decline. In the period 1998-2006, GDP growth was accompanied by a relatively slower increase in the level of GHG emissions, the differences between GDP and the GHG emission trends are mainly driven by: shifts in the structure of the economy (particularly of non-energy intensive industries); shifts in the primary energy supply (the share of oil and coal has decreased and the share of natural gas and nuclear energy has increased); a decline in activities in the agriculture and transport sectors; the decrease in population and the increase in energy efficiency.

Russia's latest energy strategy, as updated in August 2009, focuses on recovery from the current economic crisis in the 2013-2015 period. In its second phase, from 2015 to 2022, Russia would emphasize introducing new technologies and more efficiency into its energy sector. An expansion of renewable energy, including large hydroelectric plants, wind, and solar generation, would occur only in the third phase of the new strategy, from 2022 to 2030, along with continued development of hydrocarbon resources. Some steps toward the rational energy consumption will be undertaken, for example, transition to energy-saving lamps, measures for reduction of $\mathrm{CH}_{4}$ and $\mathrm{CO}_{2}$ of the biggest Russian gas enterprise Gazprom, modernization of households, etc [10]. Thereby it is not clear whether the GHG emissions will decrease or increase and thus both possibilities must be taken into account.

\section{Calculation of eco-factors}

The UNFCCC database contains data for GHG emissions for Russia, Germany and Switzerland for the period 19902009. Using equation (1), it is easy to calculate the eco-factors for the 20 year period for each of them. The results are presented below:

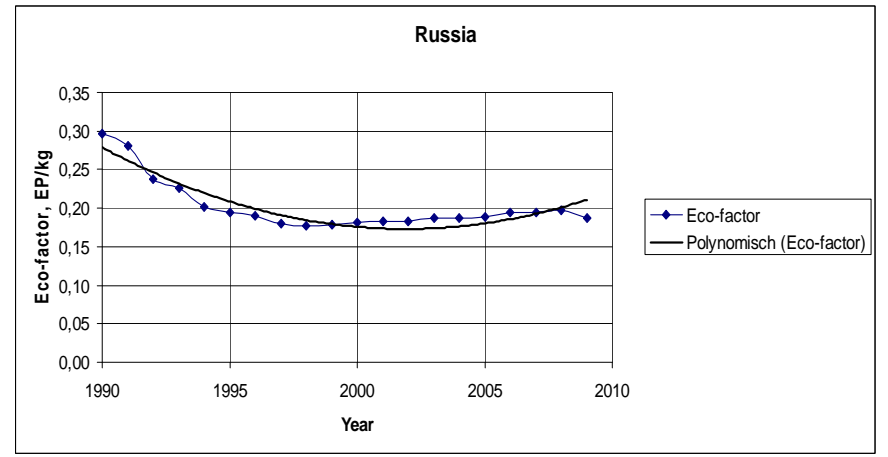

Fig. 11. Trend of Eco-factor for GHG, Russia 


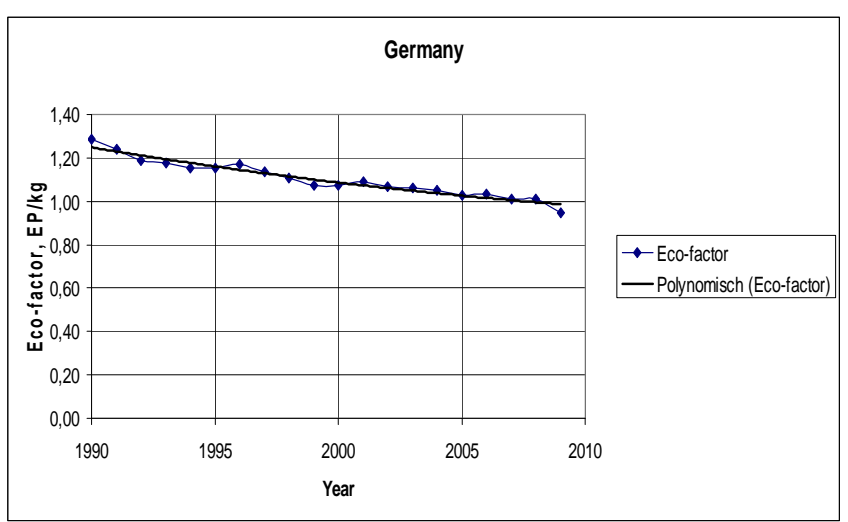

Fig. 12. Trend of Eco-factor for GHG, Germany

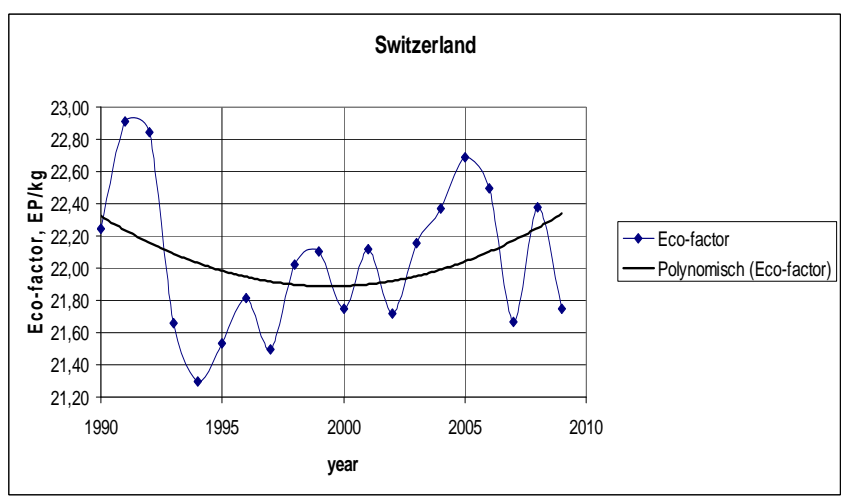

Fig. 13. Trend of Eco-factor for GHG, Switzerland

For the last inventory year of 2009, the Eco-factor for Switzerland is $21.75 \mathrm{EP} / \mathrm{kg}$ (according to Eco-factors 2006, it is $23 \mathrm{EP} / \mathrm{kg}$ ), for Germany is $0.95 \mathrm{EP} / \mathrm{kg}$, for Russia is 0.19 $\mathrm{EP} / \mathrm{kg}$. The results are quite predictable. Russia and Germany have lower value of GHG Eco-factor in comparison with Switzerland because the countries have achieved the necessary level of reduction stated in the Kyoto protocol.

The future trend is an increase in the Eco-point value because the global tendency is a further GHG emission decrease. Thus, in case of Eco-factors, the polynomial model is applicable. The trend Eco-factor function could be described as:

$$
\begin{gathered}
f_{\text {Eco-factor }}^{\text {Russia }}=0,0007 x^{2}-2,9932 x+2996,2 \\
f_{\text {Eco-factor }}^{\text {Germany }}=0,0003 x^{2}-1,0651 x+1079,7 \\
f{ }_{\text {Eco-factor }}^{\text {Switzerland }}=0,0049 x^{2}-19,653 x+19670
\end{gathered}
$$

\section{Transformation rules}

If the TR is the coefficient between the Eco-factors, it could be defined as:

$$
T R=\frac{E c o-\text { factor }^{\text {Swizerland }}}{\text { Eco }- \text { factor }^{\text {Germany }}}=22.9
$$

$$
\begin{gathered}
T R^{\prime}=\frac{E c o-\text { factor }^{\text {Swizerland }}}{E c o-\text { factor }^{\text {Russia }}}=114,5 \\
T R^{\prime \prime}=\frac{E c o-\text { factor }^{\text {Germany }}}{E c o-\text { factor }^{\text {Russia }}}=5
\end{gathered}
$$

The priority for the GHG decreasing in Switzerland should be higher than in Germany and in Russia. But the obligatory of Switzerland from the first sight is seemed to be softer than for Germany ( $8 \%$ against 21\%) nevertheless the task for Switzerland is more exigent. If create the rating how these parties carry out the Kyoto protocol responsibilities successfully it will look: 1. Russia; 2 Germany; 3. Switzerland. It is based on the ratio between the target and the achieved result.

The functional analyze gives other results for TR.

$$
\begin{gathered}
T R_{f}=\frac{f(\text { Eco }- \text { factor })^{\text {Swizerland }}}{f(\text { Eco }- \text { factor })^{\text {Germany }}} \approx 16.3 \\
T R_{f}^{\prime}=\frac{f(\text { Eco }- \text { factor })^{\text {Swizerland }}}{f(\text { Eco }- \text { factor })^{\text {Russia }}} \approx 7 \\
T R_{f}^{\prime \prime}=\frac{f(\text { Eco }- \text { factor })^{\text {Russia }}}{f(\text { Eco }- \text { factor })^{\text {Germany }}} \approx 2,3
\end{gathered}
$$

Fig. 11, 12, 13 show that Germany is the most consistent in GHG reduction. Besides that, the trend of actual flow has the same character as the trend of critical flow.

The TR rule should include the functional analyze for the more realistic result. The function indirectly includes the information about driving force for the limitation or current situation.

\section{CONCLUSIONS}

The paper is just a first attempt for the transformation rule definition and application. There is no unambiguous transformation rule. Various parameters should be taken into consideration, for example, population, economical grows, timeframe, social aspects, etc. The problem of TR is that not all the parameters can be expressed in the quantitative form and it means that analyze is not possible. In addition the situation is changing every year and these changes should be included. Strictly speaking the Eco-factors change every year, so the transformation rule is the time function also.

The degree of the influence differs from country to country. The trend of the actual and critical flows helps to identify the correspondence between special parties. The TR could be change in accordance with the function of the trend.

Each country can define its own TR and calculate ecofactors, based on national conditions and priorities.

Eco-factor is just a tool for environmental impact assessment in single score units. The transformation rule is 
one more instrument for its calculation and can be useful for countries like Russia, that have to start to carry out a new environment-oriented strategy but the environmental data base and regulation is not developed enough.

For environmentally developed countries, such as Germany, TR adjusts the EcoScarcity method widely using. The EcoScarcity is method that uses distance-to-target, could be considered as a valuation factor on the characterized midpoints results, that is, at the level of environmental problems such as global warming and others [9].

\section{REFERENCES}

1. Finkbeiner M., Inaba A., Tan R. B.H. et al. The new International Standards for Life Cycle Assessment: ISO 14040 and ISO 14044. Int J LCA, 2006, 11(2), p.80-85.

2. Frischknecht R., Steiner R., Braunschweig A., et al. Swiss Ecological Scarcity Method: The New Version 2006. http://www.esu-services.ch/

3. Miyazaki N., Siegenthaler C.P., Azuma K., et al. Practical Application of JEPIX: Method for Ecological Accounting and Life cycle Impact Assessment for Japan based on the EcoScarcity Principle, JEPIX Forum 2003. Mitaka, Tokyo,2004.

4. Miyazaki N.. Applying EcoBalance to Management Control: Combining Economic and Ecological Accounting, Second Asian-Pacific Interdisciplinary Research in Accounting Conference, 1998.

5. Ciroth A., Hagelüken M., Sonnemann G., et al. Geographical and Technological Differences in Lyfe cycle Inventories. Part I. Int J LCA, 2002, 7(5), p.295-300.

6. Nelson G. C, Bennett E., Berhe A. A., et al. Antropogenic Drivers of Ecosystem Change: an Overview. Ecology and Society 11(2): 29. [online] URL: http://www.ecologyandsociety.org/vol11/iss2/art29/.

7. Van den Berg M., Birnbaum L.S., Denison M. , et al. REVIEW: The 2005 World Health Organization Revaluation of Human and Mammalian Toxic Equivalency Factors for Dioxins and Dioxin-Like Compounds. TOXICOLOGICAL SCIENCES 93(2), 223-241 (2006)

8. THE WORLD BANK. Urban Development \& Local Government Program.

http://siteresources.worldbank.org/INTURBANDEVELOPMENT/Reso urces/336387-1169585750379/Brochure 6 pages.pdf

9. Saundry P.,Greenhouse Gas Control Policies in Russia. The Encyclopedia of Earth February 1, 2010; URL http://www.eoearth.org/article/Greenhouse_Gas_Control_Policies_in_R ussia

10. Weidema B.P., New Paradigm or Old Distance to Target? Environmental Science \&Technology . 2012,46, p.570.

11. Huijbregts M.A.J., Hellweg S., Herwich E.., Do We Need a Paradigm in Life Cycle Assessment? Environmental Science \&Technology. 2011,45, p.3833-3834.

12. Baumann H., Rydberg T.. A comparison of three methods for impact analysis and evaluation. J. Cleaner Prod. 1994, vol.2, 1, p.13-20.

13. United Nation Framework Convention on Climate Change, http://unfccc.int/2860.php

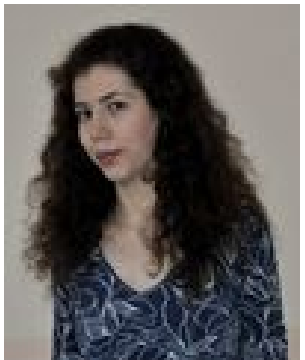

Marina Grinberg graduated from Moscow Power Engineering Institute (TU) (Moscow, Russia) with the specialization in Environmental Engineering in 2010. The Diploma research, Environmental Aspects of Industrial Lighting, was carried out as a part of the internship in thedepartment of Environmental health and Security in one of the biggest international company .

After the graduation got DAAD-Siemens scholarship for Doctoral Study at Berlin Technical University (Berlin, Germany) under the supervision of Prof. Dr. Matthias Finkbeiner. The topic of the research is Development of Ecological Scarcity: Application to Russia and Germany.

Research interests are life cycle assessment, energy efficiency, $\mathrm{CO}_{2}$ capture and storage technologies, water quality control.

Address: Strasse des 17. Juni 135, 10623, Berlin, Germany

Phone: +49 (0)30 314-29062, Fax: +49 (0)30 31421720

E-mail: marina.grinberg@mailbox.tu-berlin.de

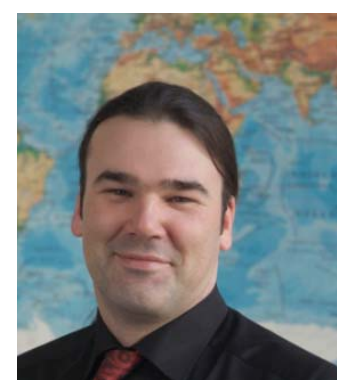

Prof. Dr. Matthias Finkbeiner is currently Chair of Sustainable Engineering and ViceDirector of the Department of Environmental Technology at Technical University Berlin. He plays a leading role in the international standardization of environmental management and is Chairman of the Portfolio Task Force of the whole ISO14000 series and Chairman of the ISO-Committee TC207/SC5 for Life Cycle Assessment. He is member of the International Life Cycle Board (ILCB) of the UNEP/SETAC Life Cycle Initiative and the Steering Committee of the Greenhouse Gas Protocol Product/Supply Chain Initiative of the World Business Council for Sustainable Development. He serves on the governing body of the ecolabel Blue Angel.

Earlier in his career, he was Manager for Life Cycle Engineering at the Design-for-Environment Department for Mercedes-Benz Cars at Daimler AG in Stuttgart. He has a multidisciplinary background of environmental science, environmental law and a MBA in sustainability management.

E-mail: matthias.finkbeiner@tu-berlin.de

Address: Straße des 17. Juni 135, D-10623, Berlin

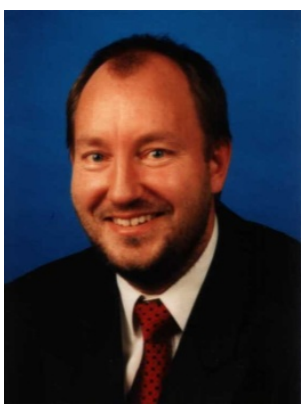

Dr. Robert Ackermann is currently working at the Chair of Sustainable Engineering. His experiences are oriented in LCA and risk assessment. Earlierer in his career, he was consultant in a consultancy office "Prof. Günter Fleischer Beratende Ingenieure" and at the academy of science of GDR. He is a environmental systemanalyst with a chemical engineering background. He studied at the technical university of Dresden.

E-mail: robert.ackermann@tu-berlin.de Address: Straße des 17. Juni 135, D-10623, Berlin 